\title{
MEMORIA E ITINERARIOS TERAPÉUTICOS DE MUJERES MIGRANTES ANDINAS EN LA CUENCA PATAGÓNICA DEL GOLFO SAN JORGE (ARGENTINA)*
}

\author{
MEMORY AND THERAPEUTIC ITINERARIES OF MIGRANT ANDEAN WOMEN \\ IN THE PATAGONIAN BASIN OF THE GULF SAN JORGE (ARGENTINA)
}

\author{
Brígida Baeza**
}

\begin{abstract}
El presente artículo analiza el modo en que un grupo de mujeres migrantes andinas quechua hablantes (provenientes de Cochabamba, Bolivia), construyen itinerarios terapéuticos donde -luego del abandono de tratamientos o de consultas médicas- comienzan a recuperar ciertas prácticas de autocuidados que remiten al modo en el que ellas o sus ancestros resolvían determinadas enfermedades y dificultades en su lugar de origen. En los procesos de recordar y resignificar prácticas andinas en contexto migratorio, también optan por acudir a determinadas prácticas de medicinas del mundo indígena patagónico.
\end{abstract}

Palabras claves: Memoria, migraciones, salud, mujeres, medicina.

This article analyzes the way in which group of quechua-speaking andean migrant women (From Cochabamb, Bolivia) construct therapeutic itineraries where-after abandoning treatments or medical consultations-they begin to recover a series of self-care practices that refer to the way they or their ancestors solved certain diseases and difficulties in their place of origin. In the processes of remembering and resignifying andean practices in a migratory context, they also choose to resort to certain medicine practices in the Patagonian indigenous world.

Key words: Memory, migrations, health, women, medicine.

\section{Introducción}

Nos interesa compartir varias problemáticas ligadas a los itinerarios terapéuticos de mujeres migrantes desde una perspectiva etnográfica en dos ciudades patagónicas argentinas, los que se enmarcan en contextos sanitarios restrictivos y expulsivos, que si bien ya hemos indagado, en este artículo profundizaremos. Y que nos han llevado a preguntarnos acerca de: ¿qué hacen estas mujeres cuando deciden desistir de los tratamientos?, ¿cómo construyen sus procesos de memoria en torno al cuerpo y a la salud en contextos de atención sanitaria restrictivos? Entre otros interrogantes que surgen a partir del trabajo de campo realizado a lo largo del 2019, y concentrado mayormente en los itinerarios terapéuticos de un grupo de mujeres ${ }^{1}$ que provienen en su mayoría del ámbito semirrural o rural de la región de Cochabamba (Bolivia). Hemos observado que en contextos de atención sanitaria restrictivos, principalmente son las mujeres las que acuden a las consultas propias o acompañando a hijos e hijas, familiares o paisanos/paisanas de la comunidad (Baeza et al. 2019).

Para el análisis del trabajo se recuperan los aportes provenientes de la antropología de la salud que busca “...basarse en una teoría de la política del sufrimiento y, de manera más general, tomar en cuenta los procesos de subjetivación que sostienen y dan sentido a las acciones"(Fassin 1999: 40). Y en especial al diálogo entre los estudios migratorios abocados al campo de la salud y los estudios de género (Da Costa Marques et al. 2016). Considerando en este caso la perspectiva feminista, se pondrá énfasis en los aportes de la teoría de la interseccionalidad, al considerar el modo en que se imbrican las distintas variables que refuerzan las desigualdades de las mujeres, a partir de la clase, raza, sexualidad, género, nacionalidad, además de lo etario, entre otros posibles componentes (Lugones

\footnotetext{
* Este trabajo forma parte de mi Plan de Trabajo "Procesos de resignificación de memoria y territorialidad de grupos migrantes quechuas en contextos de desigualdades sociales en la cuenca del golfo San Jorge, Caleta Olivia (Santa Cruz) y Comodoro Rivadavia (Chubut)", en el Consejo Nacional de Investigaciones Científicas y Técnicas.

** Instituto de Estudios Sociales y Políticos de la Patagonia, Universidad Nacional de la Patagonia. Consejo Nacional de Investigaciones Científicas y Técnicas. Dirección postal: Ruta 25. Comodoro Rivadavia (9000). Chubut, Argentina. Correo electrónico: brigida_baeza@hotmail.com
} 
2008; Viveros Vigoya 2016). Pero también desde la necesidad de generar respuestas acerca de cómo se presenta la interseccionalidad en situaciones y contextos específicos (Vivero Vigoya 2016). Sin embargo, el marco del análisis que recorre el presente artículo está dado a partir de la recuperación del concepto de memoria, en este caso vinculado al modo de representar el cuerpo, la elección de formas de cuidarlo y sanarlo. Como Carreño Calderón sostiene para el caso de los aymara del norte de Chile, importa no tanto el carácter ritual de la memoria, sino pensar el cuerpo como soporte de memoria (2015). Esa memoria presente en la transmisión de conocimientos, en el lugar que ocupan los abuelos en los modos de clasificar y pensar el cuerpo, las enfermedades y la salud, y que en contextos migratorios se resignifican bajo nuevos marcos de relacionalidad y aprendizaje.

Metodológicamente el artículo se enmarca en una concepción de investigación que busca entender y reconstruir las nociones de las personas, considerando la premisa básica "...de que los datos son siempre socialmente construidos" (Ramírez Hita 2009: 65-66). En este sentido, a lo largo de la investigación considero que se fue dando una construcción horizontal de historias que afloraron en el diálogo colaborativo (Corona Berkin y Kaltmeier 2012). Al poner de modo central el tema del cuerpo, su cuidado, las enfermedades, las sanaciones, resultaron diversos los modos de abordar el intercambio con quienes brindarons sus testimonios, en algunos casos conversaciones, en otras llamadas telefónicas, en otros casos entrevistas pautadas, observaciones, observaciones participativas. Por ser temas de alta sensibilidad y confianza merecen un agradecimiento especial a quienes compartieron ideas, conocimientos, pensamientos que requirieron de apertura pero también de ingresar en un proceso de re-conocerme a mí misma en esas historias contadas, rememoradas y compartidas en una sala de espera, en un salón de ventas, en el mercado, en sus hogares o donde surgía la posibilidad de entablar el diálogo.

\section{Acerca de sistemas, accesos y atención sanitaria en las ciudades de la cuenca del golfo San Jorge}

Así como manifestamos, el análisis estará centrado en los itinerarios terapéuticos de mujeres migrantes quechua hablantes provenientes de
Cochabamba (Bolivia), en las ciudades de Comodoro Rivadavia (Chubut), Caleta Olivia (Santa Cruz). Hemos estudiado diversas problemáticas asociadas a las barreras sanitarias (Aizenberg y Baeza 2017; Baeza y Aizenberg 2018; Baeza et al. 2019) y a diversos condicionantes que se presentan en la atención y cuidados sanitarios a los que se ven sometidas las mujeres migrantes que provienen del sector rural cochabambino y que en gran parte se trata de quechua hablantes que comienzan su proceso de aprendizaje del idioma español en las ciudades de la cuenca del golfo San Jorge (en adelante la cuenca). Las principales ciudades que la componen son Caleta Olivia (Santa Cruz) y Comodoro Rivadavia (Chubut), y se caracterizan por poseer una base monoproductiva que gira en torno a la extracción petrolera. Ambas urbes son de mediana escala poblacional y cuentan con una base poblacional heterogénea en cuanto a composición étnica y nacional, sumado a la recepción permanente de migrantes internos de diversas regiones de Argentina. Las mencionadas ciudades están separadas por $80 \mathrm{~km}$, pero la red de comunicaciones entre ellas es permanente al punto que supera el intercambio que pudieran tener con sus respectivas capitales provinciales, cuestión que se entiende no solo por la matriz fundacional petrolera que ambos centros urbanos poseen, sino también porque políticamente poseen una historia común por haber pertenecido ambas a la denominada Gobernación Militar de Comodoro Rivadavia (1944-1955).

El intercambio entre ambas ciudades también se refleja en las redes de entrelazamiento y relacionalidad de la comunidad de migrantes que provienen mayormente de Punata o Cuchupunata, (Cochabamba, Bolivia). Y también comparten diversas situaciones de discriminación y xenofobia ejercida hacia los grupos migrantes limítrofes o afrodescendientes, en particular con la comunidad boliviana, donde su adscripción indígena es una marca que genera -en ocasiones- visibilidad y rechazo. En principio, debemos considerar que las adscripciones indígenas y migrantes de estos individuos se intersectan de modo complejo en un contexto territorial urbano e industrial, diferente al del lugar de origen asociado mayormente al espacio rural. Tanto en Caleta Olivia como en Comodoro Rivadavia, la mayor parte de los hombres se emplean en el rubro de la construcción y en servicios como agencias de taxis, o bien junto 
con las mujeres en las empresas pesqueras o en el comercio callejero, en ferias, o verdulerías ubicadas en distintos puntos de ambas ciudades. Comparten las dificultades de acceso a la tierra y la vivienda junto con otros grupos sociales de sectores desfavorecidos bajo un contexto de legitimación por parte de "los pioneros" fundadores tal como sucede en otras ciudades de Patagonia, como San Carlos de Bariloche (Benclowicz, 2012).

A nivel de la atención sanitaria se caracterizan por ser contextos restrictivos que generan diversos inconvenientes y problemas que conducen a la decepción -en particular a las mujeres migrantes- y al rechazo a proseguir con tratamientos médicos o bien a realizar consultas médicas. También es necesario mencionar que en particular las mujeres atraviesan una extrema visualización dentro de determinados programas de salud, a partir de la implementación de políticas sanitarias caracterizadas por la focalización y tutela, tal como ha sido estudiado para el caso de Comodoro Rivadavia (Barría Oyarzo 2020).

En este caso particular, mostraremos cómo los procesos de memoria reflejan el agenciamiento de estos grupos migrantes, que en un contexto de desigualdades resignifican y transmiten generacionalmente no solo la ritualidad presente en curaciones y ceremonias que condensan varios significados que son relevantes al momento de analizar el modo en que se recuerda en lugares alejados al mundo andino, sino una concepción del cuerpo y de la salud que en particular les permite no solo resistir frente a determinadas prescripciones médicas sino agenciarse recuperando conocimientos y formas de entender y vincularse al propio cuerpo. En el contexto migratorio las mujeres migrantes reconstruyen aquellos conocimientos transmitidos generacionalmente en el lugar de origen, pero a partir de los marcos sociales del presente (Halbwachs 1950). Como señala Halbwachs, el tiempo presente actúa como escenario donde se desarrollan los marcos sociales desde donde se señalarán y seleccionarán los componentes de la memoria colectiva. Estos marcos sociales están definidos temporalmente, a partir de fechas de conmemoraciones, nacimientos, aniversarios, etc., que funcionan como referencia de los grupos sociales y, espacialmente, a partir de la selección de determinados lugares, objetos, donde se ha depositado la memoria de los grupos (Halbwachs 1950). Básicamente es en el contexto de situaciones límites en que se decide transmitir generacionalmente aquellos conocimientos que permiten sobrellevar, tanto en sus vidas como en las de sus familias, padecimientos y enfermedades que no logran ser comprendidas dentro del sistema médico. $\mathrm{O}$ en ocasiones, reciben tratamientos que son imposibles de proseguir por las dificultades que genera no contar con mediadores culturales que transmitan en quechua las recomendaciones médicas.

Si bien no es nuestra intención establecer un estudio comparativo entre los dos tipos de sistemas de salud presentes en los casos de Santa Cruz y Chubut, es necesario considerar al menos el modo de acceso a la atención sanitaria. Por un lado, necesitamos mencionar que en el caso de la localidad de Caleta Olivia (Santa Cruz) se accede a la atención en el sistema público de salud mediante la tramitación de un carnet hospitalario, o el pago de las prestaciones médicas, dado que se trata de un sistema arancelario ${ }^{2}$. Solo aquellas personas que pueden acceder al estatus de carenciados/ carenciadas están habilitados/habilitadas a gozar de la atención sin aranceles. Para obtener dicha categoría es necesario realizar la tramitación del carnet hospitalario, para ello hay que realizar ciertos trámites ante AFIP y demás dependencias que demuestren no contar con trabajo en relación de dependencia o ser monotributista, ya que ser reconocidos dentro de estas categorías implica contar con obra social. Entonces, el personal del sistema de salud de la ciudad de Caleta Olivia define la atención sanitaria como gratuita pero con arancel (Nota de trabajo de campo, Caleta Olivia, 12 de julio de 2019) ${ }^{3}$. En el caso de Comodoro Rivadavia (Chubut) el acceso es gratuito y no se cobra ningún tipo de arancel para la atención hospitalaria, a pesar de los sucesivos intentos de arancelamiento que sobreviven ante cualquier tipo de crisis económica que atraviese la provincia.

Además de las diferencias a nivel del acceso entre ambas ciudades patagónicas, se encuentran aquellas vinculadas a las características del trabajo en lo que refiere a la Atención Primaria de la Salud. En el caso santacruceño la legislación existente refiere con énfasis a los aspectos ligados a la prevención y profilaxis del trabajo en terreno y por sobre todo se dedica un apartado especial al modo en que se distribuirán los fondos provenientes del arancelamiento y los requisitos con los que deben cumplir las personas que tendrán a cargo el "trabajo en terreno": los agentes de salud. Básicamente se 
solicita que el/la agente cumpla con el denominado "tiempo de residencia" (Baeza 2009) o que sea nativo/nativa o que tenga cinco años de residencia ${ }^{4}$.

Las diferencias entre Caleta Olivia y Comodoro Rivadavia-que no es intención analizarlas en su profundidad- se traducen en modos de acceso al sistema de salud diferenciados, que se reflejan en las historias que pudimos analizar a partir del trabajo de campo. En el caso de Caleta Olivia la burocratización del sistema -a pesar de que se presenta como ordenado y amigable en términos de atención- genera confusión y alejamiento de quienes deben realizar algún tipo de práctica médica. Aunque como veremos en el segundo apartado de este artículo existen similitudes entre los casos, porque las dificultades sobreviven más allá del acceso a la consulta médica o a los beneficios que otorgan determinados programas de salud. La coordinadora del APS destacó los déficits y problemas que posee el sistema de salud en Santa Cruz, con falta de profesionales, escasos incentivos y sobre todo con Centros de salud (6) provinciales donde tan solo dos tienen médicos a cargo. En todos los casos quienes son directores no necesariamente son médicos, debido a que son cargos políticos. Sumado a que agentes de salud no reciben formación específica para trabajar en APS. En ambos casos también resulta significativo que los sistemas de salud no contemplan programas sanitarios con perspectiva intercultural, a pesar de que existen profesionales que poseen conocimientos acerca de las posibilidades que podría brindar en la región, no se encuentra en la agenda de ninguna de las provincias a las que pertenecen los casos analizados 5 .

Sin embargo, más allá de mayor o menor restricción en relación con el acceso al sistema de salud, veremos que las historias compartidas poseen coincidencias básicamente en torno a los enojos, frustraciones y rechazo que generan situaciones de consulta médica o tratamientos frente a determinadas enfermedades. En este sentido, consideramos que un modo de problematizar estas situaciones es por medio de la recuperación del concepto de memoria en relación con los estudios de salud, no solo porque el abordaje metodológico permite acercarnos a historias tristes, traumáticas y sensibles, sino porque consideramos que puede ser el camino para pensar desde un punto de vista que valore el pluralismo médico y se logre trascender la imposición del modelo médico hegemónico (Menéndez 2003).

\section{Itinerarios terapéuticos y procesos de memoria}

Por itinerarios terapéuticos entenderemos qué es lo que hacen las mujeres migrantes que provienen mayormente de Cochabamba (Bolivia) al momento de enfrentar un problema de salud. En particular, considerando los usos sociales de la enfermedad, los distintos componentes tanto en relación con los condicionantes como el agenciamiento de quienes deben sobrellevar los obstáculos y limitaciones que se enfrentan al momento de asistir al sistema de salud. En este sentido, interesa recuperar las experiencias personales para comprender el pluralismo médico (Perdiguero 2006). Dentro del pluralismo médico se consideran los distintos modos de entender la salud y la enfermedad, así como los diversos diagnósticos y tratamientos (Perdiguero 2006), que de acuerdo con componentes y contextos políticos y socioeconómicos varían entre los distintos grupos sociales.

En los casos analizados, si bien el acceso al sistema de salud se diferencian de acuerdo a componentes vinculados a los sistemas provinciales y municipales, una vez que ingresamos a qué es lo que sucede en el transcurso y luego de la consulta médica, vemos que los itinerarios en todos los casos están caracterizados por la sinuosidad, dificultades y problemas que se presentan ante distintas dolencias y situaciones de enfermedad. Quienes poseen recursos económicos acuden -en muchos casos- al sistema privado de salud y, como explicaremos más adelante, a buscar otros modos de sanación.

Las largas esperas se constituyen en el principal escollo para estas mujeres -tanto en el sistema público como en el privado-; la espera resulta ser una situación de agobio. Al punto que aparece en muchos relatos como la causa del alejamiento del sistema de salud y la búsqueda de otros modos de sanación, como relató Antonia, quien tiene problemas de vesícula y a quien los médicos en Caleta Olivia le recomendaron operarse:

"Estuve desde las 9 hs hasta más de las 12 hs cuando recién me atendieron... la médica de guardia me dijo: bueno si no te operas lo que tenés que hacer es dejar de comer papa, picantes y fideos, eso comen ustedes los bolivianos" (Entrevista realizada en Caleta Olivia, viernes 24 de mayo de 2019). 
A la espera entonces Antonia tuvo que sumar la respuesta que le dio la médica, y a esa situación el hecho de que tenía que pagar la operación: “...en el hospital me querían cobrar la operación, muy cara, porque a mí no me dan el carnet hospitalario..." (Entrevista realizada en Caleta Olivia, viernes 24 de mayo de 2019). Antonia fue monotributista-entonces tuvo obra social- mientras trabajaba en una planta de procesamiento de pescados, pero el cúmulo de problemas de salud que adquirió en ese trabajo ${ }^{6}$ por estar parada durante mucho tiempo y trabajar fileteando pescado en contacto con el hielo, provocó su renuncia y que decidiera emprender el proyecto de un comercio familiar. Pero el pequeño almacén del que vive ella y su familia generó que le hayan negado el carnet hospitalario, porque consideran que ella puede pagar una obra social privada.

Encontramos relatos similares a los de Antonia de modo recurrente, lo que nos remite a la confirmación de las barreras sanitarias que existen entre quienes pertenecen al campo de profesionales médicos y quienes acuden al sistema de salud, y fundamentalmente al padecimiento de ciertas violencias estructurales (Bellamy 2019) como las largas esperas para ser atendidas ${ }^{7}$. Además de las respuestas folklorizadas donde se asocia un tipo de alimentación como parte de "su cultura boliviana", y aquellas violencias asociadas a las restricciones propias del sistema de salud que generaron que Antonia desista de seguir asistiendo a las consultas médicas.

En este sentido, la historia de Antonia y de otras mujeres con situaciones similares se enmarcan en los procesos de desigualdad social que se despliegan en un conjunto de relaciones y condiciones económicas, sociales, políticas y culturales de vida que se corporifican, es decir, se inscriben en las memorias corporales, expresándose en una diversidad de experiencias y prácticas donde se reflejan procesos de desgaste-deterioro, padecimientos y formas específicos de sufrimiento social, así como en modos de interpretar, actuar y responder frente a ellos (Grimberg 2008; Goldberg 2014). Es el registro de las marcas en la memoria corporal (Cássio et al., 2019), que también se resignifican en contextos de resistencia ante la violencia y los padecimientos. Entonces, son las prácticas de autoatención a las que estas mujeres migrantes recurren por medio de la recuperación de los recuerdos del origen para resolver afecciones respiratorias leves, dolores de estómago, lastimaduras en pies, dolor de espalda y muchas afecciones que son explicadas mediante cuestiones externas a quien se encuentra afectado, pertenecen al conjunto de cuestiones que no se cuentan ni comparten a personas ajenas a la comunidad. Pero también frente a situaciones extremas como la relatada por Antonia, en este caso ella tomó la decisión de enfrentar el dolor asociando elementos de la medicina occidental y con aquellos provenientes del mundo andino factibles de encontrar en Caleta Olivia. Luego de su frustrada visita médica por su afección en la vesícula, cuando salió del hospital compró buscapina y paracetamol, se tomó todo junto y eso la alivió. También buscó las "papas secas" que se utilizan en Cochabamba para curar la vesícula, y con todo eso Antonia siente que está mejor. Ella en un tiempo se hará nuevamente la ecografía para saber si las piedras se achicaron, así no se tiene que operar. Sin embargo, también recurre semana tras semana al sahumado con koa, que consiste en un conjunto de hierbas y otros objetos que se queman en un acto ritual que se realiza regularmente en el hogar. Como explicó Antonia, lleva adelante el sahumado de su casa, donde limpia, cura y pide sus deseos, donde ella considera se concentra el poder de curarse. Es el humo que despide la quema de las plantas rituales y de varios elementos que acompañan la bandeja de sahumado que vende una de sus vecinas, donde se reúnen la comunicación de sus plegarias y el poder curativo de los mundos andinos ${ }^{8}$. Ampliando la información acerca de la koa, Antonia manifestó: "el último viernes de cada mes, pones carbón, leña y lo dejas en la casa, abrís la puerta y deja que entre el olor. Hay koa para la vivienda, para el negocio, para todo" (Entrevista realizada el viernes 24 de mayo de 2019, Caleta Olivia). La koa se puede preparar en el hogar o bien adquirirla ya lista para el sahumado, tal como se la puede observar en la Fotografía 1.

La dueña del negocio donde se venden las bandejas de koa manifiesta que ella de pequeña veía cómo su madre y su padre sahumaban su vivienda, pero que recién aprendió la práctica de sahumar estando en Caleta Olivia, su hermana, su cuñado y sus vecinas le enseñaron. A partir de distintas experiencias dolorosas que fue viviendo, sintió que era necesario aprender (Nota de trabajo de campo, Caleta Olivia, 24 de mayo de 2019). Así como sostienen los estudios pertinentes a memorias: no se recuerda en soledad, sino en contexto, en grupo, con otros y para otros. La vendedora contaba con vagos recuerdos acerca de la ceremonia del sahumado de 


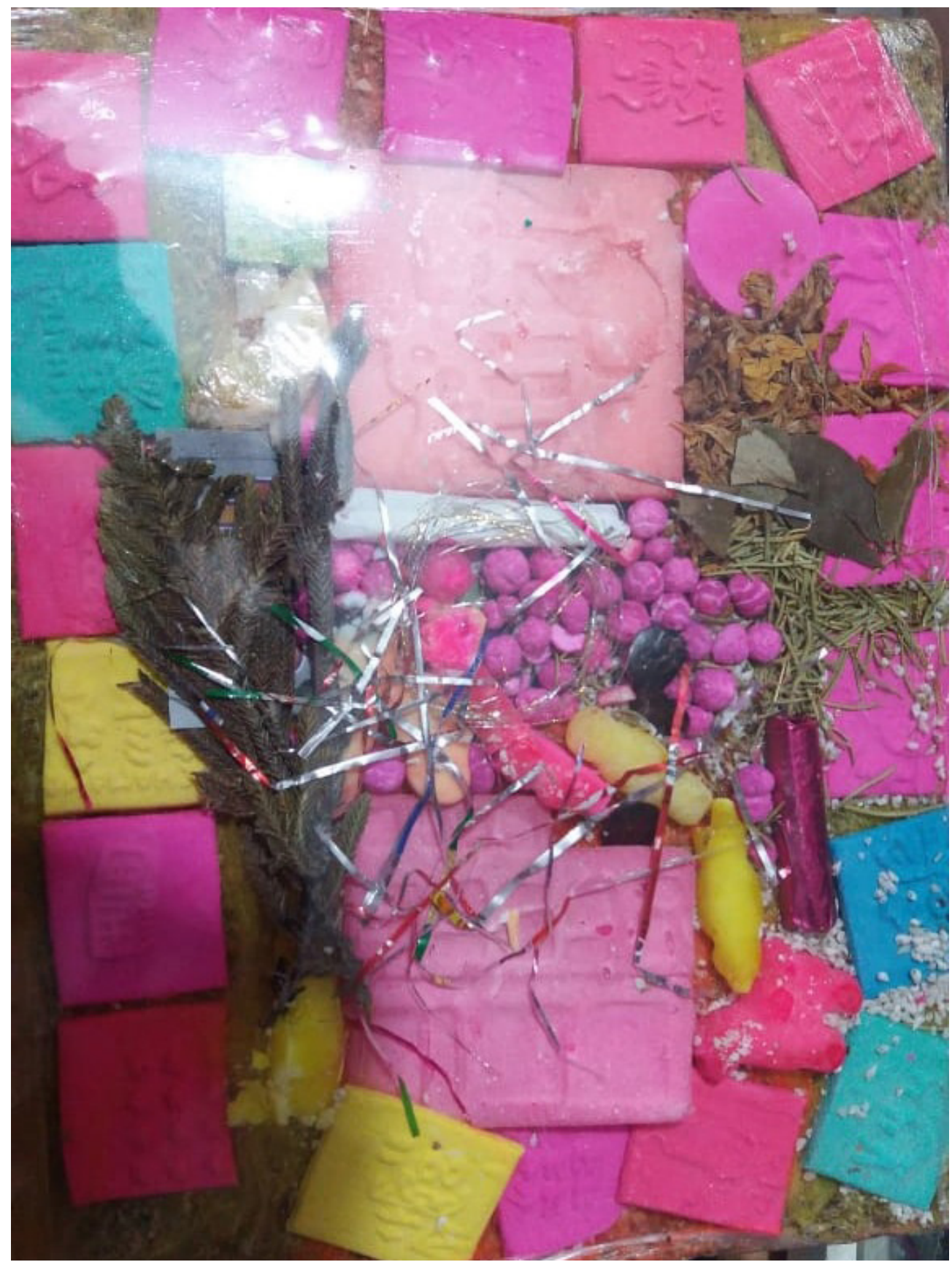

Fotografía 1. Imagen de Koa, fotografía propia.

koa, sin embargo, por tratarse de la construcción de memorias en grupos migrantes, la memoria se construye en contexto de desplazamiento, donde más importante que la "fidelidad" de los recuerdos y el cúmulo de conocimientos y verdades, lo es como objeto de reflexión en sí mismo, como "modo de experimentar el entorno" (Ramos 2011: 140).
Como se puede apreciar en el relato de la vendedora, es en el contexto migratorio donde se activan determinados conocimientos, se pregunta a quienes saben, y en particular en los momentos críticos que pertenecen al plano de los malestares corporales van siendo registrados en el plegamiento, despliegue y replegamiento de experiencias (Ramos 2017); que 
como parte del movimiento de la memoria también incorporan las marcas de dolor que subjetivamente se van construyendo y corporizando. El dolor forma parte de diferenciaciones individuales y de historias que refieren a contextos específicos donde se debió acudir a los recuerdos familiares para subsanar las dificultades de no poder contar con las personas que sanan en la comunidad de origen. De ahí la importancia de considerar las nuevas construcciones de relacionalidad (Carstens 2000), tanto con paisanos y paisanas como con otros significantes con quienes se comparten experiencias en situaciones críticas.

De todos modos, en los procesos de padecimientos se reflejan construcciones sociales del dolor, en las que se atribuye mayor resistencia a determinados grupos sociales, son aquellos que pueden "aguantar", y por esa razón refieren a padecimientos desigualmente compartidos (Otegui Pascual 2000). Entonces, se legitiman representaciones acerca de que "los bolivianos aguantan el dolor", entre otros imaginarios que reflejan que el dolor es un hecho situacional, y que aunque es íntimo “...también está impregnado de materia social, cultural, relacional, y es fruto de una educación..." (Le Breton 1999: 9). En este sentido, el cuerpo como estructura simbólica (Le Breton 1999) no es solo órganos y funciones con leyes propias del conocimiento de la anatomía, de ahí que puede tener múltiples representaciones y modos de ser abordado en situaciones de dolor y enfermedad.

En los relatos de Alda se manifiesta no solo el desentendimiento acerca del padecimiento, sino la ausencia de interés por comprender el dolor ajeno, que sumado a otras condicionantes genera que sean las dificultades y la sinuosidad lo que caracteriza a los itinerarios terapéuticos en contextos migratorios. Alda tiene 63 años, es quechua hablante y llegó a Comodoro Rivadavia hace diez años, en principio de empleó "cama adentro" en el hogar de una familia paisana y fue trayendo poco a poco a todos sus hijos e hijas. Luego organizaron un emprendimiento familiar de comercialización de frutas y verduras, donde aprendió el español en contacto con distintos sectores de la sociedad comodorense que frecuentan el negocio. Al indagar acerca de sus consultas médicas, Alda manifestó:

...no acá no voy más a los médicos, no atienden, se tardan horas y horas, un año he caminado con dolor... (se infectó el pie)... no aguanté más... me dolía, no podía ponerme nada (ni ojotas), no podía caminar, no aguanté más y le eché lavandina al pie... me paró un poco, pero después siguió, mi hija me dijo: "mamita anda al pago"...entonces he ido a Punata...el uñero, el médico enseguida me operó... está cocida su carne me dijo. Ahí me sanó en dos semanas. Me dijo que me podía agarrar un cáncer... aquí no atienden... Acá en particular no atienden, cada consulta me salió \$ 800 acá, en vano no más pagué. Solo me daban calmante (Entrevista realizada en Comodoro Rivadavia, 8 de octubre de 2019).

El hecho relatado por Alda ocurrió en el 2017, y la distancia entre Comodoro Rivadavia y Punata es de $3.790 \mathrm{~km}$. Alda -como muchas mujeres mayores que se dedican a los cuidados de los niños y niñas de las familias o al trabajo de venta en ferias o verdulerías- extraña el campo, sus animales, sus plantas comestibles y curativas, ese territorio social que es imposible recrear en su totalidad a pesar de los esfuerzos realizados. En Punata tiene la posibilidad de visitar al curandero todos los martes, alguien con quien ella compartía no solo dolencias físicas, sino su estado espiritual, sus miedos, sus dudas acerca de la vida (Notas de trabajo de campo, Comodoro Rivadavia, 8 de octubre de 2019).

La historia de Alda reafirma la necesidad de pensar el dolor-siempre de experiencia subjetiva- desde la imposibilidad de ser narrado y es ahí donde rompe con el sentido de comunidad, o bien abre la posibilidad de una nueva relación. Fue su hija quien supo interpretar que si Alda no viajaba a Punata ese dolor no cesaría. Esto nos conduce a reflexionar acerca de la relación entre memoria y dolor (Das 2008).

Múltiples historias en torno a las experiencias de frustraciones que viven las mujeres con las que abordamos sus itinerarios terapéuticos generan que se deje como última instancia la consulta médica, y se recurre a lo que Menéndez denomina primer nivel real de atención (1992), donde se activan la experiencia vivida en situaciones similares, tanto propias como de vecinos, vecinas, paisanos, paisanas y otros grupos cercanos que se van sumando a sus redes de relacionalidad. Es el proceso denominado por Menéndez como de autoatención (2003) y que da cuenta de lo grupal, social y en constante modificación que posee el hecho de recurrir a 
conocimientos propios y que están estrechamente vinculados con la transmisión generacional de los procesos de memoria. En particular, las poblaciones andinas urbanas de Bolivia recurren fuertemente a la autoatención, así como lo muestra Ramírez Hita en el caso de las comunidades quechuas que residen en Potosí, donde se combinan pobreza y un sistema de salud deficitario (Ramírez Hita 2005). Y donde también debemos considerar las clasificaciones de las enfermedades existentes en el mundo andino, así como el modo en que se diagnostican, previenen y curan (Ramírez Hita 2005). Básicamente la enfermedad aparece por un desequilibrio causado por un desorden de la naturaleza que puede tener su origen en un "mal" de otra persona, de un espíritu o algún castigo divino; pudiendo ser las enfermedades de tipo corporales o espirituales. Sin embargo, las enfermedades espirituales pueden derivar en enfermedades corporales.

Todos estos registros operan al momento de decidir a qué especialista consultar en primer término, o si es posible en un inicio resolver la situación de enfermedad al interior de las familias. A lo largo de nuestro trabajo de campo fuimos viendo que resulta crucial para lograr afrontar la enfermedad, el modo en que se van sorteando las dificultades que deben afrontar quienes acuden al sistema de salud. El trayecto está plagado de dificultades y no todo el grupo de migrantes puede acceder a niveles de la atención hospitalaria de mayor complejidad, tal como compartió Raúl su experiencia, a raíz del problema de salud de su hija. Raúl lleva toda una vida en Comodoro Rivadavia, es un referente de la comunidad proveniente de Cochabamba y de otros lugares de Bolivia, y posee contactos a nivel consular como con los distintos niveles gubernamentales locales. Raúl tiene una hija adolescente que desde niña baila en los grupos de danzas de la comunidad, y hace alrededor de cinco años su hija enfermó de epilepsia. Raúl relata:

Así hasta que por intermedio de quien era Ministro de Salud: Dr. Corchuelo Blasco en el gobierno de Buzzi, consiguieron el avión sanitario para trasladar a su hija a Buenos Aires, donde confirmaron que era epiléptica (Entrevista realizada el 18 de mayo de 2019, Comodoro Rivadavia).

El itinerario hasta llegar a la consulta en Buenos Aires donde su hija fue medicada de acuerdo con su enfermedad, duró alrededor de dos años porque en Comodoro Rivadavia dudaban de que fuese epiléptica, al punto que Raúl tuvo que amanecer noches enteras esperando el brote del ataque para dejar registros fílmicos de los momentos del ataque para mostrar a los médicos. En el último período de ataques su hija llegó a tener 9 desmayos en un día. Sin embargo, la familia deseaba realizar un viaje a Bolivia para poder consultar a los médicos kallawayas en La Paz. Como el viaje se demoraba, un sobrino de Raúl viajó especialmente a Comodoro Rivadavia, a dejar el pajarito que cura la epilepsia, luego de dos intentos fallidos logró pasar la frontera con el pajarito y una vez aquí, su hija tomó la sangre y luego se cocinó el pajarito y se lo convirtió en polvo que ella también ingirió 9 . Luego de idas y venidas finalmente llegó el momento del viaje a Bolivia, en principio necesita cumplir con su promesa de participar del carnaval de Oruro, donde bailó horas y horas sin parar y lo más importante sin desmayos. Entre 2016 y 2017 -junto con su madre- su hija pasó todo el verano sin problemas en Bolivia, vivió una experiencia única que hizo que ella decidiera querer ir a vivir a Bolivia. No alcanzaron a ir a ver los médicos kallawayas, por la distancia y porque el estado de salud había mejorado notablemente. Luego de pasar por todos los itinerarios mencionados su hija pudo tener una vida normal, actualmente regresó a la escuela y espera terminar sus estudios para una vez jubilado Raúl puedan vivir en Bolivia. Ella sintió que "ese es su lugar" (Notas de trabajo de campo, 18 de mayo de 2019, Comodoro Rivadavia).

El relato de Raúl y su hija adolescente nos introduce en dos aspectos que aquí nos interesa resaltar, por un lado el modo en que se presenta el pluralismo médico, donde conviven en forma simultánea, se solapan y complementan distintas tradiciones en el modo de enfrentar una situación de enfermedad y en el problema de la transmisión generacional, lo que nos enfrenta al momento de analizar cómo se desarrollan los procesos de transmisión de memorias. Resulta interesante ingresar al mundo de cómo determinado grupo o comunidad decide la transmisión generacional, porque implica considerar la epistemología del secreto (Berliner 2005) que comprende aquellas cuestiones que la gente mayor decide vedar y no transmitir, así ese hálito de lo oculto y del misterio genera aún mayor curiosidad en el deseo de los grupos jóvenes. Es en esos momentos críticos en que se decide la 
transmisión, y que permite por esta razón el acceso a la curación. La hija y el sobrino de Raúl son jóvenes que ante el trauma que generaba la enfermedad intervinieron activamente en la solución. Ese conocimiento adquirido seguramente -hoy resguardado- será activado nuevamente frente a determinadas situaciones críticas propias o de sus paisanos y familia.

Sin duda, la transmisión generacional amerita mayor profundización, ya que en ocasiones hemos visto un proceso de silenciamiento y ocultamiento de aquellos conocimientos que remiten a curaciones y la posesión del "don" de curar. Entonces, es necesario considerar las dificultades que se suscitan a partir de la indagación acerca de la producción de silencios y el modo en que se decide su perduración (Dwyer 2009); para ello se requiere indagar en las políticas del silencio (Dwyer 2009) que refieren a resistencias muchas veces ligadas al hecho de generaciones forzadas a olvidar. Como el caso de una cochabambina que posee profundos conocimientos del poder curativo de plantas, de partes de animales, sumado al don de curar, transmitido generacionalmente en Cochabamba al interior de su familia, pero que en contexto migratorio sus propios hijos han condenado por considerar prácticas "de indios", entonces es necesario ocultar (Baeza y Oyarzo 2020).

En otro orden, hemos abordado las resistencias expresadas por medio del silencio, para el caso del parto de mujeres quechua hablantes (Baeza, 2013). Los procesos de embarazo, parto y puerperio -como fueron investigados para el caso de mujeres colla para la zona de Atacama (Chile)-, están atravesados por el cuidado del cuerpo y la maternidad colectiva atendiendo a "...la preservación de la ancestralidad y la desmedicalización de los procesos femeninos, transformándose así en su principal estrategia de resistencia cultural descolonizadora" (Rodríguez Venegas y Duarte Hidalgo, 2020: 113).

\section{Autocuidado y pluralismo médico}

Tal como fuimos observando en las experiencias de itinerarios médicos de las historias que compartimos, es en las múltiples dificultades y obstáculos que las mujeres migrantes deben ir sorteando que se encuentra la posibilidad de recurrir al autocuidado, a la pesquisa de soluciones mediante prácticas que traen desde sus lugares de origen así como de redes con otros lugares de residencia de sus paisanos y paisanas o bien a redes establecidas con familiares del lugar de origen. También fuimos viendo las dificultades que existen en la transmisión generacional y las posibilidades de acceder a los yatiris (médicos andinos), porque al interior de las familias y el temor a ser denunciados por práctica ilegal de la medicina, genera que se recurra a otras posibilidades, entre las que se encuentra la consulta a curanderas nativas ligadas al mundo rural mapuche-patagónico.

A lo largo del trabajo de campo surgieron referencias de una curandera en particular, a quien logré acceder. Ella reside en la zona sur de la ciudad en un barrio contiguo al de mayor concentración de población migrante cochabambina, atiende por turnos $\mathrm{y}$ en su casa donde tiene montado un consultorio que se encuentra ambientado con olores e imágenes del mundo curativo. Muchas de las imágenes de vírgenes como la de Urkupiña fueron obsequio de migrantes de Cochabamba en agradecimiento por las curaciones realizadas. Sus conocimientos los adquirió por transmisión de su padre mapuche de Buta Ranquil (Neuquén, Argentina). Dentro de sus prácticas se encuentra "tirar" las cartas, curar el empacho, la ojeada, la culebrilla, el susto y sobre todo posee una diversidad de conocimientos acerca del poder curativo de plantas medicinales. Las mujeres migrantes cochabambinas están entre los principales grupos que asisten a consultarla respecto de múltiples dolencias, las que para ella tienen su origen en los procesos de cambios a nivel de la vida cotidiana que desarrollan en Comodoro Rivadavia. Se refirió particularmente al hecho de que el progreso económico genera diferencias entre las familias, que aquí los hombres se vuelven soberbios y encaran un tipo de vida machista (tener amantes, querer gastar el dinero en bienes superfluos, golpearlas).

La curandera compartió el relato de un episodio con una familia cochabambina, que acudió a ella desesperada por la enfermedad de un niño:

...justo mi marido no estaba entonces no tenía auto para ir al Hospital Regional, entonces vinieron ellos a buscarme. Y me llevaron al Hospital, ahí encontré al nene casi moribundo, ya no tenían muchas expectativas con él. Lo vi muy mal. Ellos me hicieron pasar por una tía y así me dejaron entrar. Después nos arreglamos para que no me viesen cuando lo curaba. Y así fue que lo salvé. Esa familia hasta el día de hoy sigue viniendo a agradecerme (Entrevista 
realizada en Comodoro Rivadavia, 31 de mayo de 2019).

Sin duda, estas y otras historias que catapultan a la curandera como referente de las mujeres cochabambinas, genera que sus curaciones se difundan y sea reconocida tal como un yatiri (médico andino). Uno de los elementos que mayor interés despertó es que la curandera ofrece la posibilidad de compartir sus conocimientos, al conocerme sintió que existe interés por difundir prácticas que hasta el momento deben estar ocultas en la intimidad del hogar y al resguardo de quienes condenan los conocimientos ancestrales.

Conocer a la curandera nos permitió ingresar al mundo de la convivencia de distintos modelos médicos, sus cruces, intersecciones, solapamientos, disputas, tensiones, pero por sobre todo reconocer que los modelos del pluralismo médico conviven en paralelo y que en las experiencias de las mujeres cochabambinas termina siendo efectivo aquel que no forma parte del sistema hegemónico. Las situaciones aquí relatadas nos conducen a recuperar el interrogante de Knipper cuando se pregunta acerca de:

...si la meta es brindar atención digna y de calidad para todos los pacientes, es necesario dinamizar tanto las mentes como las estructuras. Pero mientras en el campo de la medicina la categoría "cultura" no deje de ser percibido como algo exótico, apto para excluirlo, por ejemplo, en "sistemas" e instituciones paralelas a la "medicina académica", queda mucho por hacer (Knipper 2006: 427).

En los relatos de las experiencias de las mujeres entrevistadas predomina la confusión que generan los tratamientos médicos que se recetan sin mediación de intérpretes de la lengua quechua ${ }^{10} \mathrm{y}$ sin confirmación de que la transmisión y explicación sea exitosa. Entonces, luego de las consultas se regresa al hogar sin saber qué sucedió, cómo se denomina la enfermedad y qué acciones se pueden ir desarrollando para recuperar el cuerpo enfermo. Como sucedió con Isidra, una cochabambina de 50 años, que se presenta como una mujer robusta, que parió 5 hijos sola en su casa y que está atravesando un problema de salud, del que le dijeron que fue "...un ACV. Me sentía mareada, cuando estaba parada lavando me lloraba un ojo y el otro no (el derecho). Cuando quería dormir ese ojo no se cerraba" (Entrevista realizada en Comodoro Rivadavia, 22 de mayo de 2019). Según Isidra le recetaron pastillas. Le pregunté si le habían dado rehabilitación y me dijo que no. Le dijeron que tenía que volver para saber cuándo le darían los turnos, ella regresó al Hospital Regional pero no le dijeron nada. En esas interminables idas y venidas al hospital, Isidra decidió consultar a la curandera, ahí sí está recibiendo respuestas a sus dudas, sus demandas y lentamente cesa el desconcierto. Sus familiares manifiestan que desde que comenzó a visitar a la curandera, Alda se siente mejor (Notas de trabajo de campo, 23 de mayo de 2019).

De modo similar al caso de Alda, la combinación de tratamientos de los distintos modelos médicos es la forma en que estas mujeres deciden sobrellevar sus padecimientos o los de sus hijos e hijas. Ante la drástica decisión de no acudir más al sistema de salud -de acuerdo con las circunstancias y eventos de enfermedad-, las mujeres deciden enfatizar más uno u otro modelo. Como manifestó Rosalía, una cochabambina joven pero que lleva veinte años residiendo en Argentina, quien manifestó que ella no va al médico, que realmente la cansaron, que le tocó estar horas y horas en el hospital o en una clínica privada para que no le digan nada, para que le den unas pastillas y la envíen a su casa inmediatamente. Rosalía mostró un amplio conocimiento de la herbolaria nativa que utiliza para sustituir la andina, ante mi asombro manifestó: "pasa que nosotros somos ciegos" (Entrevista realizada en Comodoro Rivadavia, 23 de mayo de 2020). En esa frase Rosalía sintetiza el efecto que ha generado el empleo de medicamentos de laboratorios, que nos impide ver las posibilidades que brinda el empleo de las plantas medicinales -que se encuentran alrededor nuestro-que ella reencontró en contexto migratorio.

\section{Conclusiones}

En términos del capital económico adquirido por las mujeres migrantas provenientes de Cochabamba, Bolivia, se podría afirmar que cuentan con alternativas de asistir al sistema de salud público o privado, este último por contar con obra social o bien por contar con recursos económicos que les permite abonar las consultas. Sin embargo, el acceso no refleja el cese de la violencia estructural que recae sobre ellas y amerita ser explicada. Y uno de los modos resulta 
ser por medio del concepto de interseccionalidad aplicado al análisis de salud y género, porque permite cuestionar la supuesta homogeneidad de grupos poblacionales o la tipificación de determinados grupos migrantes. En el caso de las mujeres migrantes andinas, es necesario considerar sus prácticas sanitarias previas a la migración, donde también opera el complejo resultado de las estructuras de dominación social y de discriminaciones históricas (Kapilashrami y Hankivsky 2018), y que en el contexto migratorio se agravan por las distancias sociales vinculadas a diversos condicionantes, entre las que se encuentran las barreras del lenguaje. El concepto de interseccionalidad también nos recuerda la mayor visibilidad que poseen las mujeres frente a los hombres migrantes - por ser quienes asisten solas o con sus hijas e hijos-, por estar expuestas a las largas esperas y colas para sacar turnos, ser responsables de comprender o no los tratamientos y sostenerlos en el tiempo, de la alimentación en sus hogares, además de sostén económico único en demasiados casos. En muchas de estas prácticas como las de sostener colas y esperas durante horas, son discriminadas de modo positivo por los profesionales de la salud, sin embargo, nuevamente se enfatiza un aspecto vinculado al "aguantar" frente a las horas de esperas o ser duras frente al dolor.

En ese contexto, son las mujeres quienes resguardan la memoria corporal con mayor énfasis, para ello deben resistir no solo ante las miradas controladoras institucionales, sino también contra quienes propugnan el blanqueamiento que borraría lo andino en un contexto de vida urbana e industrial.

Nuestro trabajo intentó mostrar que resta mucho por hacer, académicamente nos encontramos en la etapa inicial de estudiar el modo en cómo se presenta el pluralismo médico entre las comunidades migrantes andinas que provienen de Bolivia. Sin duda, intenta ser un aporte al desarrollo de políticas sanitarias que desde los distintos niveles de atención de la salud breguen por mayor inclusión de modos de entender el cuerpo y el malestar y que no concuerdan con el sistema médico hegemónico.

Los esfuerzos en pensar políticas interculturales en el campo de la salud, sin duda requiere apelar a perspectivas que consideren la transmisión de la memoria intergeneracional, desde el análisis de todos sus componentes, considerando esos olvidos estratégicos que los grupos han decidido, los silencios y omisiones, las historias tristes, los eventos traumáticos, los recuerdos que son necesarios evocar, entre otros componentes de los procesos de memorias de grupos subalternizados. Como un camino a considerar la interculturalidad sin perder el carácter crítico y emancipativo que debe contener, para evitar la inclusión subordinada (Viaña 2009), que reproduciría las lógicas de las desigualdades ya existentes que reforzaría la dominación. En este sentido, es imperioso fortalecer las frágiles estructuras políticas (Mondaca Rojas y Gajardo Carvaja, 2015) con las que poder profundizar el diálogo intercultural. Pero también considerar la agencia de aquellas personas de las comunidades que como referentes culturales asumen el rol de mediadores o facilitadores culturales en el ámbito de la salud intercultural. Así como se da en el caso de aymaras en el campo de la salud intercultural en el norte de Chile, donde en la “...performance democrática puesta en acto por los agentes de salud indígena es parte de la lucha por la definición de las fronteras del campo intercultural..." (Carreño y Freddi 2020: 39).

En este sentido, consideramos que indagar en la memoria corporal permite analizar experiencias que en algunos casos quedarán transitoriamente suspendidas en los intersticios de los dobleces, mientras otras, formando la superficie, articularán sentidos entre sí. A partir del análisis de las múltiples conexiones que se establecen a partir de los movimientos de las experiencias en torno a los recuerdos, ocultamientos, olvidos estratégicos, silencios, es posible transcender la visión de nostalgia que envuelve al origen. Al contrario, aquí se mostró que en contextos migratorios el agenciamiento mediante la potencia que adquieren determinadas prácticas de la memoria corporal, brinda herramientas para sobrellevar las dificultades propias de contextos de atención sanitaria caracterizados por las restricciones. Y de ese modo evitar y disminuir las situaciones traumáticas y que pueden costar la vida.

\section{Agradecimientos}

Agradezco especialmente a las mujeres que contribuyeron a que este artículo sea posible, a las instituciones que financian mis investigaciones, en particular al Consejo Nacional de Investigaciones Científicas y Técnicas y a la Secretaría de Ciencia y Técnica de la Universidad de la Patagonia. Y a los aportes de colegas y evaluadores que permitieron enriquecer este artículo. 


\section{Referencias Citadas}

Aizenberg, L. y Baeza, B.

2017 "Reproductive health and bolivian migration in restrictive contexts of access to the health system in Córdoba, Argentina", en Health Sociology Review, 26, 3.

Baeza, B., Aizenberg, L. Oyarzo Barría, C.

2019 "Salud migratoria: miradas comparativas entre profesionales sanitarios y mujeres migrantes bolivianas", en $\mathrm{Si}$ Somos Americanos. 19,1, pp. 43-66.

Baeza, B.

2009 Fronteras e identidades en Patagonia Central. Prohistoria, Rosario.

Barría Oyarzo, C.

2020 "Memoria y territorialidad quechua-punateña en 'el zanjón'”, en Rodríguez, M. y Ramos, A. (Comps.) Memorias fragmentadas en contexto de lucha. Editorial Teseo, Buenos Aires. Pp. 340-365.

Barría Oyarzo, C.

2020 "Gestión de políticas públicas en salud: Mujeres migrantes en una ciudad de la Patagonia, Argentina". Revista Anthropologica, 38(44)

Bellamy C, Castro R.

2019 "Formas de violencia institucional en la sala de espera de urgencias en un hospital público de México". RevCienc Salud. 17(1): 120-137. doi: http://dx.doi.org/10.12804/ revistas.urosario.edu.co/ revsalud/a.7621

Bellamy C, Castro R.

2019 "Formas de violencia institucional en la sala de espera de urgencias en un hospital público de México". RevCienc Salud.; 17(1): 120-137. doi: http://dx.doi.org/10.12804/ revistas.urosario.edu.co/ revsalud/a.7621

Berliner, D.

2005 "An 'Impossible' Transmission: Youth Religious Memories in Guinea-Conakry". American Ethnologist, 32 (4), 576-592.

Benclowicz, J.

2012 "Migraciones y representaciones populares en una ciudad turística. Notas sobre San Carlos de Bariloche, Argentina". Diálogo Andino. 40: 83-96.

Carreño Calderón, A.

2010 Cuerpos y almas migrantes: ensayos sobre la noción de persona andina y la gestión del sufrimiento en nuevos territorios. VII Congreso Chileno de Antropología. Colegio de Antropólogos de Chile A. G, San Pedro de Atacama.

Carreño Calderón, A.

2015 "La gentilidad de los abuelos: memoria, enfermedad y cuerpos imaginados en los Andes chilenos". En Acerca de la (des)memoria y su construcción en Mesoamérica y Andes, editado por Sergio Botta, Clementina Battcok, pp. 353-398. México: Quivira.

Carreño Calderón, A. y Freddi, A.

2020 "Performativizar la democracia: salud y enfermedad como espacios de acción política entre los aymaras del norte de Chile". Diálogo Andino, No 62: 31-40.

Carsten, J.

2000 Cultures of Relatedness. New Approaches to the Study of Kinship. Cambridge: Cambridge University Press.

Cássio Silveira (Silveira, C.); Denise Martin (Martin, D.); Alejandro Goldberg (Goldberg, A.)

2019 "La vida confeccionada entre retazos de tela: trabajo, vivienda y salud en inmigrantes bolivianos de la ciudad de
São Paulo". Trabajo y Sociedad, Revista Sociología del Trabajo-Estudios Culturales-Narrativas, Sociológicas y Literarias, $\mathrm{N}^{\circ} 32$

Corona Berkin, S. y Kaltmeier, O.

2012 En diálogo. Metodologías horizontales en Ciencias Sociales y Culturales. Gedisa. México.

Da Costa Marques, S., Linardelli, M. y Maure, G.

2016 La relación entre antropología médica crítica y estudios feministas y de género: notas para una discusión. Jornadas Nacionales de Investigación en Ciencias Sociales de la UN, Cuyo. Perspectivas actuales en la investigación en ciencias sociales, Mendoza, Argentina. https://bdigital.uncu.edu. ar/9879 (10 de junio de 2020).

Dwyer, L.

2009 "A politics of silences: violence, memory and treacherous speech in post-1965 Bali”. En A. L. Hinton y K. L. O'Neill (Eds.), Genocide, Truth, Memory and Representations (pp. 113-146). Durham: Duke University Press.

Fassin, D.

1999 "La patetización del mundo. Ensayo de antropología política del sufrimiento". En M. Viveros, G. Garay (comp.), Cuerpo, diferencias y desigualdades (págs. 31-44). Facultad de Ciencias Humanas, Universidad Nacional de Colombia.

Viveros Vigoya, M.

2016 "La interseccionalidad. Una aproximación situada a la dominación". Debate feminista, 52, 1-17. https://doi. org/10.1016/j.df.2016.09.005

Fassin, D.

2004 "Entre las políticas de lo viviente y las políticas de la vida. Hacia una antropología de la salud". Revista Colombiana de Antropología 40, 283-318.

García-Moreno C., Hegarty K., Lucas d'Oliveira A.F., KoziolMcLain J., Colombini M., and Feder G.

2015 "The health-systems response to violence against women". Lancet. 385: 1567-79.

Kapilashrami A, Hankivsky O.

2018 Intersectionality and why it matters to global health. The Lancet. 391:2589-2591. DOI: 10.1016/ S0140-6736(18)31431-4

Knipper, M.

2006 'El reto de la 'medicina intercultural' y la historia de la 'medicina tradicional' indígena contemporánea". En: Fernández Gerardo (comp.), Salud e interculturalidad en América latina. Antropología de la salud y crítica intercultural. Quito: ABYA YALA, UCLM, AECI. Pp. 413-432.

Le Breton, David

1999 Antropología del dolor, Barcelona, Seix Barral.

Lugones, $\mathrm{M}$.

2005 "Multiculturalismo radical y feminismos de mujeres de color". Revista Internacional de Filosofía Política (25), 61-76.

Lugones, $\mathrm{M}$.

2008 "Colonialidad y género". Tabula Rasa (9), 73-101. https://doi.org/10.25058/20112742.340

Menéndez, E.

1992 La antropología médica en México. Universidad Autónoma Metropolitana, México.

Menéndez, $\mathrm{E}$.

2003 "Modelos de atención de los padecimientos: de exclusiones teóricas y articulaciones prácticas”. Ciência\&Saúde Coletiva, 
vol. 8, núm. 1, pp. 185-207 Associação Brasileira de PósGraduaçãoemSaúdeColetiva Rio de Janeiro, Brasil.

Carlos Mondaca Rojas y Yeliza Gajardo Carvajal

2015 "Interculturalidad, migrantes y educación". Diálogo Andino, $\mathrm{N}^{\circ}$ 47: 3-6.

Perdiguero, E.

2006 "Una reflexión sobre el pluralismo médico", en Gerardo Fernández Juárez (Coordinador), Salud e Interculturalidad en América Latina Antropología de la salud y Crítica Intercultural. Ediciones Abya-Yala Quito-Ecuador.

Pizarro, C., Fabro, F. y Ferreira, M.

2016 Los discursos laborales legitimados y las prácticas de migrantes bolivianos en relación al mercado laboral en su lugar de trabajo: el cortadero de ladrillos en una zona rural de Córdoba. Ponencia presentada en el 9no. Congreso Nacional de Estudios del Trabajo.

Sumonte Rojas, V., Sanhueza Henríquez, S., Friz Carillo, M. y Morales Mendoza, K.

2018 "Migración no hispanoparlante en Chile: tendiendo puentes lingüísticos e interculturales". Diálogo Andino $\mathrm{N}^{\circ}$ 57: 57-67.

Ramírez Hita, S.

2009 "La contribución del método etnográfico al registro del dato epidemiológico. Epidemiología sociocultural indígena quechua de la ciudad de Potosî’. Revista Salud Colectiva, 5(1):63-85, Buenos Aires.

Ramírez Hita, S.

2005 Donde el viento llega cansado. Sistemas y prácticas de salud en la ciudad de Potosí, La Paz, Bolivia, Cooperación Italiana.

Ramos, A.

2017 "Cuando la memoria es un proyecto de restauración: el potencial relacional y oposicional de conectar experiencias". En A. Bello, Y. González y O. Ruiz (Eds.), Historias y memorias. Diálogos desde una perspectiva interdisciplinaria (pp. 32-50). Temuco: Ediciones Universidad de la Frontera, Colección Espiral Social, Núcleo de Ciencias Sociales y Humanidades.

Rodríguez Venegas, V. y Duarte Hidalgo, C.

2020 "Saberes ancestrales y prácticas tradicionales: embarazo, parto y puerperio en mujeres colla de la región de Atacama". Diálogo Andino $\mathrm{N}^{\mathrm{o}}$ 63: 113-122.

Rosario Otegui P.

2000 "Factores socioculturales del dolor y el sufrimiento". Enrique Perdiguero y Josep M. Comelles (eds.), Medicina y cultura. Estudios entre la antropología y la medicina. España, Ed. Bellaterra-SGU.

Saletti-Cuesta, L. and Aizenberg, L.

2019 Intersectional innovative analysis of how providers'discourses interact with universal healthcare access. En: Tavares, AI. Universal Health Coverage. Intech Open.Enprensa.

Saletti-Cuesta, L. Ferioli, A., Martínez, F.V., Viel, E., Baudin, V., Romero, P. Funk, N. González, A.C., Rodríguez, A.

2019 "El abordaje de la violencia de género desde la mirada de las comunidades del norte cordobés". Cadernos de Saudé Pública. En prensa.

TRADUCCIÓN Jeanne Favret- Saada: "ser afectado" como medio de conocimiento en el trabajo de campo antropológico Avá versión On-line ISSN 1851-1694 Avá no.23 Posadas dic. 2013.

Viaña J.

2009 La interculturalidad como herramienta de emancipación. Hacia una redefinición de la interculturalidad y de sus usos estatales. La Paz. Campo Iris.

Notas

1 Si bien se hará referencia mayormente al trabajo de campo del 2019, también se recuperarán notas de campo del 2017 y 2018. Los nombres de las mujeres y el hombre entrevistado (padre de una adolescente con un grave problema de salud) fueron modificados para resguardar su identidad personal.

2 En 1988 la provincia de Santa Cruz creó el fondo de asistencia financiera al sistema provincial de salud, mediante la Ley 2901, que si bien tuvo modificatorias a lo largo del tiempo, básicamente sigue sosteniendo el cobro de aranceles por atención y prestaciones médicas a todas aquellas personas que no logren demostrar ser carenciados.

3 En un cartel que figura en la puerta de ingreso a la oficina de atención para la realización de los trámites del carnet hospitalario, se detalla toda la documentación a presentar con énfasis en que en caso de "Extranjeros con precaria en mano", entre otros requisitos. Hospital Zonal de Caleta Olivia, Santa Cruz. La "precaria" es la documentación que permite residir temporariamente en Argentina, habilitando a residir, estudiar y trabajar legalmente.

4 En el caso de Santa Cruz en 2018 se aprobó la Ley 3621 de fortalecimiento y jerarquización de la atención primaria de la salud en la provincia de Santa Cruz En: https://aldiaargentina.microjuris.com/2018/11/15/ fortalecimiento-y-jerarquizacion-de-la-atencion-primaria-dela-salud-provincia-de-santa-cruz/(Consulta realizada el 22 de agosto de 2019). Para el caso chubutense, la legislación provincial no hace referencia a este tipo de requisitos y sí se pone énfasis en el perfil profesional. En: Organización del trabajo en terreno. Dirección de Promoción y Prevención. Secretaría de Salud. Chubut. Año 2007.

$5 \quad$ Notas de trabajo de campo, 21 de agosto de 2019, Caleta Olivia, Santa Cruz. Y para el caso de Chubut podemos citar el Ciclo de Seminarios y debate en salud pública, organizado por la Secretaría de Extensión de la FNyS UNPSJB, Trelew. Chubut. 18 de octubre de 2019.

6 Antonia adquirió várices y otros problemas asociados al contacto con el hielo, como la artritis.

7 Las investigaciones acerca del sufrimiento social fueron realizadas con grupos de trabajadores migrantes en talleres textiles provenientes de Bolivia, Argentina y Brasil.

8 https://chucalezna.wordpress.com/tag/coa/

9 Evidentemente se trató de la jurkuta: "La sangre del murciélago y de la paloma de los Andes o Jurkuta todavía se utiliza como uno de los remedios más populares contra la epilepsia en Cochabamba. Los cazadores las entregan vivas para que los curanderos obtengan el líquido para sus 
pacientes". Violeta Soria: "Usan animales silvestres para 'curas milagrosas', Cochabamba", en: "Los Tiempos", http://www.lostiempos.com/actualidad/local/20160508/ usan-animales-silvestres-curas-milagrosas
10 No se registran experiencias con Mediadores Lingüísticos, agentes que contribuirían a construir espacios de intercambios desde una perspectiva intercultural. Como el caso con ML haitianos en Chile (ver Sumonte Rojas, 2018). 